\title{
A pesquisa em educação popular e a Educação Básica
}

\section{Research in popular education and Basic Education}

\section{La investigación en educación popular y la Educación Básica}

\section{Danilo Romeu Streck ${ }^{*}$}

Resumo: O artigo analisa a relação entre educação popular e Educação Básica, com atenção especial ao impacto das pesquisas em educação popular nas políticas e práticas de Educação Básica. Inicialmente, reflete-se sobre a educação popular como um campo de pesquisa no qual, a partir de práticas de investigação e educação, se desenvolve uma proposta metodológica com características próprias. O segundo tópico da reflexão consiste na reconstituição da relação entre educação popular e Educação Básica como dois campos de práticas pedagógicas que se movimentam entre o formal, o não formal e o informal. O parâmetro para a análise são os trabalhos apresentados em reunião da ANPEd (Associação Nacional de Pós-Graduação e Pesquisa em Educação). Como conclusão, são apontadas algumas tarefas emergentes para a atividade de pesquisa em educação popular e suas implicações para a Educação Básica.

Palavras-chave: Educação popular. Educação Básica. Pesquisa participante.

\begin{abstract}
This paper analyses the relation between popular education and Basic Education, focusing mainly on the impact of popular education research on policies and practices of basic education. Initially, a reflection is proposed about popular education as a field of research in which, from investigation and education practices, a methodological proposal with singular characteristics is developed. The second theme for reflection is the reconstitution of the relation between popular education and basic education as two fields of pedagogical practices which vary from formal, non-formal and informal. The parameters of analysis are works presented in the ANPEd (PostGraduation and Educational Research National Association) meeting. Results point to some emerging tasks for the popular education research and their implications to basic education.
\end{abstract}

Keywords: Popular education. Basic Education. Participatory research.

Resumen: El artículo analiza la relación entre educación popular y Educación Básica, con atención especial al impacto de las investigaciones en educación popular en las

\footnotetext{
* Professor do Programa de Pós-Graduação em Educação da Universidade do Vale do Rio dos Sinos Unisinos. E-mail: <dstreck@unisinos.br>
} 
políticas y prácticas de educación básica. Inicialmente, se reflexiona sobre la educación popular como un campo de investigación en el cual, a partir de prácticas de investigación y educación, se desarrolla una propuesta metodológica con características propias. El segundo tópico de la reflexión consiste en la reconstitución de la relación entre educación popular y educación básica como dos campos de prácticas pedagógicas que se mueven entre lo formal, lo no formal y lo informal. El parámetro para análisis son los trabajos presentados en reunión de la Asociación Nacional de Postgrado e Investigación en Educación (ANPEd, pos sus siglas en portugués). A modo de conclusión, se señalan algunas tareas emergentes para la actividad de investigación en educación popular y sus implicaciones para la educación básica.

Palabras clave: Educación popular. Educación Básica. Investigación participante.

\section{Observações preliminares}

Este texto se insere no desafio de compreender a relação entre a pesquisa nas áreas clássicas em que se divide a atividade investigativa na pós-graduação e a Educação Básica. ${ }^{1}$ Parte-se do pressuposto de que os pesquisadores e as pesquisadoras, embora reconhecendo a especificidade de sua atividade, não podem estar alheios à realidade da Educação Básica. Dada a abrangência do tema, são necessárias algumas observações preliminares para evitar que eventualmente sejam reforçados argumentos simplistas que colocam a pesquisa em educação e a prática educativa em lados opostos ou buscam subordinar uma à outra.

A primeira questão preliminar consiste em problematizar a natureza da relação entre pesquisa e prática. Há uma evidente brecha entre o que hoje se sabe sobre a educação no Brasil e a realidade da Educação Básica. Por outro lado, não há uma linha direta entre a produção de conhecimento e a prática, nem tampouco se pode extrair conhecimentos da prática com o entendimento que através do devido "tratamento científico" por especialistas esses conhecimentos terão o poder quase mágico de transformar a prática. Existem "porosidades" entre a produção acadêmica e a prática pedagógica e as políticas educacionais, mas há temporalidades distintas, mediações diferentes e interesses que podem coincidir ou conflitar (MALTA, 2009).

Sabe-se, no entanto, que o divórcio entre teoria e prática é tanto resultado quanto sintoma de uma situação histórica já denunciada por Simón Rodríguez (2006, p. 192), o mestre de Simón Bolívar. Dizia ele: “Grandes projetos de

\footnotetext{
${ }^{1} \mathrm{O}$ texto foi elaborado, como trabalho encomendado, para o Grupo de Trabalho de Educação Popular do IX Encontro de Pesquisa em Educação da Região Sul - ANPEDSUL, cujo tema geral foi A pós-graduação e suas interlocuções com a Educação Básica. Os dados apresentados têm por base projeto de pesquisa que conta com o apoio do CNPq e da FAPERGS. Colaboraram na pesquisa os seguintes bolsistas de iniciação científica: Letícia da Silva (FAPERGS), Jonas Hendler da Paz (CNPq), Andressa Espíndola (CNPq) e Vinícius Masseroni (UNISINOS). Essa é uma versão ampliada e revisada do texto publicado no livro do congresso da ANPED Sul: A pós-graduação e suas interlocuções com a Educação Básica, organizado por F. B. Ramos, N. M. S. Paviani e T. M. de Azevedo (Editora UCS, 2012).
} 
ILUSTRAÇÃO! Ao lado de uma absoluta IGNORÂNCIA contrastarão sempre e nunca se associarão - juntos, fazem um MONSTRO SOCIAL". Denunciava também como "mera fantasia" os conhecimentos teóricos sem a respectiva prática, uma vez que a teoria é "o conjunto de preceitos dados por uma experiência consumada" (RODRÍGUES, p. 181). Romper essa dicotomia tem sido uma das preocupações metodológicas da educação popular, tanto na pesquisa quanto na prática educativa.

Uma segunda questão preliminar diz respeito à terminologia. $O$ conceito de Educação Básica está estabelecido na legislação ${ }^{2}$, o que garante certa unanimidade de compreensão quanto ao seu funcionamento e estrutura, mas não consegue proporcionar um sentido unívoco ao que é o básico da educação. Este, como sabemos, está inscrito nas contradições e conflitos que perpassam a sociedade. Classes sociais, grupos étnicos e interesses regionais procuram atribuir seus significados próprios ao que deveria ser o básico. Além disso, a crescente complexidade da sociedade moderna e o ritmo das inovações tecnológicas impõem um caráter de transitoriedade ao básico. As permanências se tornam menos perceptíveis e tendem a ser ofuscadas pela avalanche de novidades.

$\mathrm{Na}$ educação popular, encontramos semelhante dificuldade de precisão conceitual. Como bem o expressou Adriana Puiggrós (2010, p. 39), “o significante da educação popular habita de modo conflitivo os discursos sociais, culturais e educativos". Mais do que isso, habita os imaginários de transformação e por isso mesmo talvez não se deixe prender em definições limitadoras. Historicamente o conceito serviu como bandeira para a educação pública na América Latina e vemos juntos, na luta pela educação popular (no sentido de educação para todos), pessoas de campos políticos diferentes, como é o caso do argentino Domingo Faustino Sarmiento e do cubano José Martí, o primeiro defendendo uma campanha civilizatória nos moldes europeus para combater a barbárie e o segundo argumentando que a verdadeira questão não era a disputa entre civilização e barbárie, mas entre a natureza dos povos - sua história e modo de viver - e a falsa erudição. Apenas na década de 1950 é que o conceito passa a ter a conotação que hoje se lhe atribui. Isso não significa que na proposta de educação popular anterior não possam ser reconhecidos os antecedentes da atual educação popular, em especial nas fontes ocultadas ou silenciadas pela história hegemônica.

Neste estudo buscamos analisar a relação entre educação popular e Educação Básica, tendo como perspectiva tanto a pesquisa quanto a prática

\footnotetext{
${ }^{2}$ No Art. 22 da Lei de Diretrizes e Bases da Educação Nacional, lê-se: "A Educação Básica tem por finalidades desenvolver o educando, assegurar-lhe a formação comum indispensável para o exercício da cidadania e fornecer-lhe meios para progredir no trabalho e em estudos posteriores." (BRASIL, 1996). Trata a seguir dos diversos níveis e formas de organização.
} 
educativa. A premissa é que a educação popular é um movimento pedagógico de resistência à dominação, seja ela de classe, de raça, de gênero ou outras. Mas ela é ao mesmo tempo um movimento de ação propositiva e de criatividade, o que procuramos expressar com a noção de incidência, que pode referir-se às práticas educativas em diversos âmbitos, às políticas públicas e à própria forma de pesquisar. Isso significa que a educação popular e a Educação Básica podem estar, do ponto de vista ideológico e pedagógico, no mesmo campo ou em campos opostos.

Inicialmente apresenta-se breve reflexão sobre a educação popular como um campo de pesquisa no qual se desenvolve uma proposta metodológica. Temos já uma vasta bibliografia que reflete sobre as práticas de educação popular e aponta as mudanças ocorridas nas últimas décadas (PALUDO, 2001; TORRES CARRILLO, 2007; MEJÍA; AWAD, 2007; WANDERLEY, 2010). Menos conhecimento se tem dos rumos da pesquisa na área. Um segundo tópico da reflexão consiste na reconstituição da relação entre educação popular e Educação Básica como duas práticas pedagógicas que se movimentam entre o formal, o não formal e o informal, ou - se preferimos - entre o escolar e o não escolar. Na terceira parte do texto, apresentam-se alguns dados relativos à pesquisa sobre os lugares da educação popular, considerando especialmente a relação com a Educação Básica. Como conclusão, são apontadas algumas tarefas emergentes especialmente para a atividade de investigação nas quais convergem os interesses da educação popular e da Educação Básica.

\section{Educação popular e método de pesquisa}

A educação popular tem, para além de uma incidência direta sobre a prática educativa e das políticas públicas em educação, uma contribuição importante na pesquisa da área. A própria criação da Associação Nacional de Pós-Graduação e Pesquisa em Educação (ANPEd), em 1976, teve o forte protagonismo de educadores e pesquisadores identificados com a educação popular, constando o Grupo de Trabalho (GT) de Educação Popular entre os primeiros a serem estruturados pela entidade. ${ }^{3}$

Uma dessas contribuições diz respeito à metodologia de pesquisa que, na educação popular, não pode ser dissociada dos temas a serem pesquisados. Trata-se de uma mudança de atitude em relação ao campo empírico cujos habitantes passam a ser protagonistas no processo de produção de conhecimento sobre a sua realidade. Experiências em lugares diferentes, geralmente sem

\footnotetext{
${ }^{3}$ O primeiro coordenador do GT de Educação Popular da ANPEd foi Osmar Fávero. Para uma breve história do GT de Educação Popular da ANPEd, veja o livro Travessia: Questões e perspectivas emergentes na pesquisa em educação popular (COSTA; FREURI, 2001).
} 
articulações explícitas entre si e com vinculações pouco elaboradas com propostas de investigação em outros continentes, começaram a constituir um campo epistemológico e metodológico próprio.

No Brasil, a pesquisa participante nasce como irmã gêmea da educação popular, sendo hoje a experiência de alfabetização de Paulo Freire em Angicos considerada também uma experiência precursora da pesquisa participante. Os temas geradores não eram "inventados" em laboratórios acadêmicos, mas recriados a partir do diálogo entre especialistas (sociólogos, linguistas, psicólogos e educadores) e membros da comunidade. "A investigação da ação do pensar do povo não pode ser feita sem o povo, mas com ele, como sujeito de seu pensar." (FREIRE, 1981, p. 119). Os educadores tinham um papel que Paulo Freire definiria como diretivo no processo de codificação e decodificação, uma vez que se tratava de propiciar a seus concidadãos - que com certeza sabiam mais do que eles de seu próprio mundo - um novo código (o escrito) para ler e dizer o seu mundo.

Um dos pesquisadores que mais contribuiu para popularizar a pesquisa participante no Brasil é Carlos Rodrigues Brandão, uma referência fundamental para quem compreende a pesquisa como um processo partilhado de desconstrução, construção e reconstrução de conhecimentos na ação transformadora e emancipadora. ${ }^{4}$ Participação, para este autor, refere-se tanto à partilha dos momentos do processo de produção do conhecimento quanto ao empoderamento dos sujeitos dos movimentos sociais populares. De forma resumida, a pesquisa participante integra quatro propósitos assim definidos por ele:

a) ela responde de maneira direta à finalidade prática a que se destina, como meio de conhecimento de questões a serem coletivamente trabalhadas;

b) ela é um instrumento dialógico de aprendizado partilhado e, portanto, [...] possui organicamente uma vocação educativa e, como tal, politicamente formadora;

c) ela participa de processos mais amplos e contínuos de construção progressiva de um saber popular e, no limite, poderia ser um meio a mais na criação de uma ciência popular;

d) ela partilha, com a educação popular, de toda uma ampla e complexa trajetória de empoderamento dos movimentos populares e de seus integrantes. (BRANDÃO, 2006, p. 46).

Na Colômbia, o sociólogo Orlando Fals Borda popularizou o nome de Pesquisa-Ação Participante (em espanhol "Investigación Acción Paticipativa IAP). Conforme ele, "a metodologia da IAP é integrativa, isto é, não é apenas

\footnotetext{
${ }^{4}$ O livro Pesquisa participante: o saber da partilha (BRANDÃO; STRECK, 2006) contém uma bibliografia de textos fundantes e atuais e de sites dessa metodologia de pesquisa (p. 277-296).
} 
um método de pesquisa, nem apenas uma forma de chegar aos grupos de base, aos adultos, nem tão pouco apenas uma forma de ação política. É uma combinação dessas três formas de procedimento" (FALS BORDA, 2010, p. 206). Denunciava que a produção científica estava perpassada por interesses de classe e que o silenciamento dos saberes dos povos originários, das comunidades de campesinos e dos trabalhadores não possibilitaria o desenvolvimento de uma ciência autêntica, no sentido de estar fundada nas necessidades do povo e comprometida com a transformação da sociedade na ótica da justiça social.

Com isso, a atividade investigativa sai dos muros da academia e passa a se integrar nas práticas sociais e pedagógicas de organizações e grupos populares. Desenvolve-se desde a década de 1970 um amplo e diversificado movimento de "sistematização de experiências" que tem como objetivo compreender a lógica das experiências e, junto com o conhecimento dessas, potencializar a sua capacidade de transformação da sociedade. Entre os elementos comuns destacados pelos diferentes enfoques de sistematização podemos encontrar os seguintes: o diálogo como princípio metodológico básico; a criação de condições para participação de todos os sujeitos, o que originou uma grande diversidade de estratégias, instrumentos e dinâmicas; a reconstrução da memória coletiva como fator de identidade; a análise do contexto social, cultural e econômico no qual se insere determinada experiência; o desenvolvimento de estratégias de ação transformadora; a (re)construção da teoria a partir da prática (JARA, 2006; TORRES CARRILLO, 2010).

$\mathrm{Na}$ pesquisa em educação popular desenvolvida no contexto acadêmico, essas metodologias nem sempre são de fácil aplicação, dada a não coincidência de agenda de pesquisadores e grupos. Desde a definição de temas para dissertações, teses e projetos de pesquisa, aos prazos para a conclusão dos trabalhos, há uma série de fatores que dificultam uma aplicação mais rigorosa dessa metodologia, especialmente no contexto da escola. Elas aparecem muito mais como um pano de fundo inspirador com vistas aos princípios que têm em comum com a educação popular. É muito comum ver, em teses e dissertações, explicitada a opção pela pesquisa participante, sem, no entanto, desenvolver o caráter da participação na definição do problema, na análise dos dados e, sobretudo, na avaliação dos resultados para a comunidade, grupo ou escola. Muitas vezes, a participação está na intencionalidade militante do pesquisador e da pesquisadora. Tomando-se como referência as duas dimensões da participação identificadas por Carlos Rodrigues Brandão, poder-se-ia dizer que a dimensão da participação está centrada mais no engajamento em favor da mudança com os sujeitos de pesquisa do que na produção coletiva do conhecimento. A pergunta é se com a separação dessas duas dimensões não se está reproduzindo a mesma lógica de investigação criticada pela pesquisa participante. 
De modo geral, verifica-se a presença permanente, embora escassa e pouco sistematizada, da reflexão crítica sobre o processo realizado, buscando identificar inovações conceituais e práticas. Nas reuniões anuais da ANPEd, entre 1999 e 2010, encontramos os seguintes trabalhos que abordam temas metodológicos de uma forma mais direta: Gonsalves (2001); Gonçalves (2003); Wunder (2003); Amâncio (2004); Rodrigues e Castro (2005); Falchembach (2007); Brayner (2008); Adams (2009); Tavares (2009); Cunha (2009); Melo Neto (2010); Moretti (2010).

Na ANPEd-Sul, a partir de 2002, encontramos os seguintes trabalhos: Rodriguez (2004); Kieling (2004); Azibeiro e Perassa (2004); Lambach (2006); Machado e Paludo (2010); Adams e Streck (2010).

Os trabalhos anteriormente referidos indicam a preocupação sobretudo com questões epistemológicas. Há uma busca de incorporar elementos teóricos novos que abrangem uma ampla gama de perspectivas epistemológicas, como Humberto Maturana, Boaventura de Sousa Santos, Edgar Morin e Michel Foucault. Verifica-se também um movimento de sintonizar com o pensamento "descolonial" na América Latina através de autores como Walter Mignolo e Alejandro Quijano.

Há, no entanto, muitos temas fundamentais que carecem de reflexão. Como exemplo, um tema que mereceria atenção é a relação entre o princípio dialógico da pesquisa participante indicado em muitos projetos e o poder exercido pelos diferentes participantes do processo de pesquisa. Estaria a pesquisa criando um espaço livre de relações de poder? Ou estariam estas sendo ofuscadas por discursos de igualdade construídos pelo pesquisador ou pesquisadora? Há ainda outras perguntas de caráter mais coletivo a serem respondidas: Onde se origina a agenda de pesquisa em educação popular? A partir de onde e com quem são construídos os problemas de pesquisa das dissertações, teses e projetos dessa área? Qual é a efetiva relação que se estabelece entre os pesquisadores e as práticas?

Numa reunião com membros da comunidade de Saucío, município do Chocontá, na Colômbia, onde Orlando Fals Borda realizou a sua primeira experiência de pesquisa-ação participativa (ROJAS GUERRA, 2010), ${ }^{5}$ estes relataram detalhes da pesquisa que resultou na construção na cooperativa e da escola que hoje abriga os arquivos do pesquisador. O trabalho foi realizado em 1959 e hoje este processo de produção coletiva de conhecimento e de mudança de sua realidade continua vivo na memória do povo da região. É como se dissessem que essa comunidade não foi mais a mesma depois de participar

\footnotetext{
${ }^{5}$ Nessa reunião no ano de 2010, acompanhei o pesquisador Alfonso Torres Carrillo, da Universidade Pedagógica Nacional da Colômbia, que discutiu com estes membros da comunidade a criação de um centro de pesquisa e formação.
} 
no conhecimento de si, de seu mundo, de suas dificuldades e potencialidades. Experiências evidentemente não são reproduzíveis, mas este fato pode ser visto como um marco do que se pode entender como impacto da pesquisa a partir da educação popular.

\section{Práticas de educação popular e Educação Básica}

Observamos até este ponto a educação popular como lugar onde se gera, junto com a prática educativa, uma metodologia de investigação. Tratase de um movimento que busca fazer da pesquisa um processo coletivo, com envolvimento das pessoas e grupos implicados como sujeitos no processo de conhecer e transformar a sua realidade. Focaremos, a seguir, a relação entre práticas educativas no âmbito da educação popular e da Educação Básica.

A compreensão atual de educação popular na América Latina remonta às décadas de 1950 e 1960. No Brasil, são desenvolvidas as campanhas de alfabetização, o Movimento de Educação de Base (FÁVERO, 2006; PAIVA, 2009), o Movimento de Cultura Popular (BARBOSA, 2009) e uma série de atividades culturais, políticas e pedagógicas imbuídas do espírito de mudança. Convivem, nesse período inicial, as ideias de complementaridade entre iniciativas de diferentes contextos educacionais e de transformação, que Paulo Freire expressa muito bem no seu conceito de trânsito. Por um lado, há uma crença na possibilidade de que a emergência de sujeitos políticos a partir de massas silenciadas ao longo de séculos promova, dentro das permanências, as rupturas que levem à construção de democracias. Como se trata de um movimento de transformação dentro do sistema, não se estabelece uma contradição com as redes de escolas e universidades, que tiveram segmentos fortemente engajados na mudança da sociedade. Não pode ser esquecido que Paulo Freire realiza a sua prática de alfabetização em Angicos a partir de seu posto de professor na Universidade de Recife. ${ }^{6}$

Por outro lado, alerta Freire, nem toda mudança é trânsito: este implica sempre mudanças qualitativas. Ele coloca a questão nos seguintes termos:

Nutrindo-se de mudanças, o tempo de trânsito é mais do que simples mudança. Ele implica realmente nesta marcha acelerada que faz a sociedade à procura de novos temas e de novas tarefas. E se todo Trânsito é mudança, nem toda mudança é Trânsito. As mudanças se processam numa mesma unidade de tempo histórico qualitativamente invariável, sem afetá-la profundamente. (FREIRE, 1980, p. 46).

\footnotetext{
${ }^{6}$ A Universidade do Recife mais tarde se transforma na Universidade Federal de Pernambuco. Na época, Paulo Freire atuava como diretor do Departamento de Extensão Cultural da Universidade.
} 
O fato de grafar Trânsito com letra inicial maiúscula acentua a busca do qualitativamente distinto, que naquele período histórico parecia viável através da mobilização popular, da qual a educação era parte. A educação popular, mesmo que não com esse nome, estava se constituindo como uma matriz pedagógica que ao mesmo tempo alimentava o trânsito e era formada a partir das mudanças anunciadoras de trânsito para uma sociedade aberta e democrática.

Há uma mudança significativa na compreensão de educação popular com a instalação das ditaduras militares na América Latina. Desaparece a ideia de complementaridade e as práticas educativas dirigidas principalmente ao público adulto tomarão cursos distintos, respondendo ao conflito entre os campos políticos: por um lado, a manutenção da ordem em função do crescimento da economia, mesmo que implicando o desrespeito aos direitos civis e humanos; por outro lado, a busca de alternativas que passassem pela construção da cidadania e de uma sociedade mais igualitária.

O conceito de libertação serviu para abrigar as diferentes lutas sociais e as diferentes áreas de conhecimento. Há uma confluência teórica baseada, sobretudo na prática social dos "movimentos de base" e menos em disputas sobre autores e conceitos. A ortodoxia acadêmica cedeu lugar à ortopráxis, aproximando comunicadores, teólogos, sociólogos, artistas, educadores e outros profissionais.

Muda-se também a visão a respeito da escola. Se antes era um lugar que precisava ser complementado por causa de suas deficiências e ineficiências, agora ela passa a ser um lugar perigoso. O livro Cuidado Escola! (HARPER, 1980) é a expressão do tipo de pensamento que se tornou comum em relação à escola. $\mathrm{Na}$ crítica à escola se juntaram várias vertentes que de certa forma penetraram a educação popular e ajudaram a construir a sua visão de escola e de educação fundamental, vindo muitos desses argumentos paradoxalmente servir os interesses conservadores de desestabilização e enfraquecimento da escola. Uma das vertentes críticas foi o "reprodutivismo" que teve como referências Louis Althusser, em especial o seu livro, Ideologia e os aparelhos ideológicos do Estado (1992), Pierre Bourdieu e Claude Passeron (1982), com a obra A reprodução. De outro lado, na perspectiva dos avanços tecnológicos e das novas possibilidades de organização do ensinar e aprender, temos Ivan Illich (1973), com o seu clássico Sociedade sem escolas.

Se essas ideias não entraram na formulação sistematizada de uma teoria da educação popular, elas certamente contribuíram para deslocar o foco da atenção para fora da escola. Num texto que é referência da época, Carlos Rodrigues Brandão (1977, p. 33) escrevia "Da educação fundamental ao fundamental da educação", argumentando que se precisava ir além da ideia de que o básico se restringia aos conhecimentos para garantir condições materiais de vida, mas se 
entendesse o básico como a possibilidade de homens e mulheres participarem como sujeitos na criação de uma "verdadeira ordem social e humana." O autor referia-se às experiências do Movimento de Educação de Base, criado no início da década de 1960 por iniciativa da CNBB e que tinha como público-alvo os setores marginalizados da sociedade. Essas experiências criaram uma densidade de práticas e de reflexões que sobreviveu ao desmantelamento institucional promovido pelas ditaduras militares.

O processo de redemocratização do país não pode ser dissociado da educação popular, que em boa medida se constituiu na dimensão pedagógica da luta política. A década de 1980 é um período em que surgem muitos centros de educação popular, centros de documentação, centros de formação nos quais se gestavam propostas que depois viriam a ser integradas em políticas públicas e se formavam lideranças de movimentos sociais e movimentos populares, muitos dos quais mais tarde viriam a militar em partidos políticos de esquerda.

Um dos lugares de incidência desses centros foi a nova constituição nacional, promulgada em 1988. Defendia-se o ensino público, laico e gratuito em todos os níveis e para todos os cidadãos. Enfatizam-se os direitos humanos, o desenvolvimento da capacidade de reflexão crítica sobre a realidade, a educação profissional, oferta de creches e defendia-se a elaboração de um plano Nacional de Educação (BAGGIO, 2006, p. 308-313). Algumas dessas questões estão hoje incorporadas através de políticas públicas e outras continuam como bandeiras de luta.

A partir da assunção ao poder de partidos de esquerda começa a se desfazer a distância entre a educação popular com grupos "de base" e a escola, que passa de responsável pelo Ensino Fundamental para principal promotora da Educação Básica. Emblemática para a mudança de atitude em relação à escola é a aceitação por Paulo Freire do convite da Prefeita Luiza Erundina, para assumir a Secretaria Municipal de Educação em São Paulo, em 1989. Em Educação na cidade (1991), Paulo Freire defende uma escola pública, democrática e popular, uma escola séria e alegre, que não exclua as crianças e os jovens das classes populares.

A escola pública que desejo é a escola onde tem lugar de destaque a apreensão crítica do conhecimento significativo através da relação dialógica. É a escola que estimula o aluno a perguntar, a criticar, a criar; onde se propõe a criação de um conhecimento coletivo, articulando o saber popular e o saber crítico, científico, mediados pela experiência do mundo. (FREIRE, 1991, p. 83).

A experiência de São Paulo coincidiu com a experiência em outros lugares onde educadores experimentaram "mudar a cara da escola", o que se expressa em nomes como "escola cidadã", que teve Porto Alegre como um dos lugares pioneiros (AZEVEDO et al., 2000; BRANDÃO, 2002), "escola candanga" 
(Brasília, DF), Escola sem Fronteiras (Blumenau, SC), Escola Guaicurú (estado do Mato Grosso do Sul) (GADOTTI, 2003). Outras experiências, muitas vezes sem um nome próprio, buscaram criar espaços dentro da rede oficial de ensino nos quais os princípios da educação popular pudessem ser concretizados e recriados. O mapeamento e estudo dessas experiências seriam importantes tanto para a educação popular quanto para a Educação Básica.

Como visto, a contribuição da educação popular para a Educação Básica se dá para além da luta pela garantia do acesso à escola. Há uma constante preocupação com os critérios de qualidade. Nélida Céspides (2005), a partir do CEAAL (Conselho de Educação de Adultos da América Latina), onde a incidência em políticas públicas em educação tem sido uma das linhas de ação, identificou os seguintes indicadores de qualidade a partir da educação popular:

- desenvolve aprendizagens que empoderam os sujeitos educativos como sujeitos de direitos e responsabilidades;

- situa-se na perspectiva de promover processos de transformação num mundo marcado pela injustiça;

- pode-se medi-la por sua opção ética, que significa que a educação popular é uma práxis em constante renovação e se apresenta como elemento de alternativa;

- parte da realidade social, cultural, política dos sujeitos para voltar a ela, transformando-a;

- considera a cultura como fundamental para a sua qualidade;

- impulsiona processos de autoafirmação;

- promove um saber prático-teórico;

- gera produção de conhecimento;

- existem professores e professoras que, como profissionais da educação, decidem fazer de sua profissão um ato de responsabilidade pública e promotor dos direitos da infância;

- e existe o estado e o governo que promovem políticas e programas de educação que assegurem o direito de todos e de todas à educação. (CÉSPIDES, 2005, p. 26).

$\mathrm{Na}$ ampliação da ideia de Educação Básica, há também a confluência de fatores e experiências internacionais. A já citada Declaração de Jomtien, no artigo primeiro, postula que cada indivíduo deve ter condições de satisfazer as necessidades básicas de aprendizagem que incluem conteúdos, valores e a possibilidade de participar ativamente de sua sociedade. "A Educação Básica é mais do que uma finalidade em si mesma. Ela é a base para a aprendizagem e o desenvolvimento humano permanentes, sobre a qual os países podem construir, sistematicamente, níveis e tipos mais adiantados de educação e capacitação" 
(Art. 1, 4). À Declaração de Jomtien, segue-se o relatório Jacques Delors (1999) que sublinha a compreensão ampliada da Educação Básica a partir de quatro pilares da educação: aprender a conhecer, aprender a fazer, aprender a conviver e aprender a ser.

Um campo onde a relação entre educação popular e a Educação Básica se encontram e desencontram de forma especial é na educação de jovens e adultos (EJA). Essa está hoje incorporada como uma modalidade de ensino dentro da Educação Básica. As discussões sobre EJA repercutem em boa medida os mesmos problemas sentidos pela escola regular: alta taxa de evasão de alunos, indefinições curriculares, além da falta de professores especificamente preparados para essa modalidade de ensino.

Uma tentativa de conectar a educação de jovens e adultos com a educação popular é o MOVA, criado inicialmente em São Paulo e depois replicado em outros estados. Em São Paulo, ele foi criado no governo da Prefeita Luiza Erundina pelo Decreto n. 28.302, de 21 de novembro de 1989. Sua criação correspondia à confluência de interesses da Secretaria Municipal de Educação e de movimentos populares que estavam envolvidos ou interessados em promover atividades de alfabetização ou pós-alfabetização. No Rio Grande do Sul, o MOVA foi criado no ano de 1999 (BRANDÃO, 2001), pautado nos mesmos princípios que articulavam a dimensão política, humana e técnico-científica. Estudos apontam avanços no sentido de organização da sociedade civil para uma ação mais propositiva e menos reivindicatória; ao mesmo tempo, constatam que a parceria se reveste da cultura autoritária, paternalista e clientelista, da qual estão imbuídos tanto os sujeitos do governo quanto da sociedade civil (SALES, 2010).

No governo Lula, em conexão com o Programa Fome Zero, foi criada a Rede de Educação Cidadã (RECID), que busca a articulação de diversos atores sociais, entidades e movimentos populares do Brasil "que assumem solidariamente a missão de realizar um processo sistemático de sensibilização, mobilização e educação popular da população brasileira e principalmente de grupos vulneráveis econômica e socialmente (indígenas, negros, jovens, LGBT, mulheres etc.)" ${ }^{7}$ Estão envolvidos nesse processo mais de 550 organizações e entidades da sociedade civil cujo trabalho se pauta em princípios e metodologias de educação popular. Trata-se de uma contribuição da educação popular para ensaiar outras formas de Educação Básica, em outros espaços.

Essa breve análise mostra que Educação Básica e educação popular não são intercambiáveis e uma não pode ser concebida como dependente da outra. A educação popular teve um papel importante em ampliar e radicalizar o sentido do básico, especialmente na década de 1980 (WERLE, 1996), lutando pela

\footnotetext{
${ }^{7}$ Ver < http://www.recid.org.br/organizacao.html>. Acesso em: 03 abr. 2012.
} 
inclusão da dimensão educativa em políticas públicas e enfatizando a necessidade de conteúdos e metodologias que promovessem a solidariedade, a cooperação e participação social. Hoje, as parcerias com o estado representam novos desafios para a educação popular e para a sua relação com a Educação Básica.

Um dado significativo é que nas últimas décadas vem crescendo o interesse em pesquisar a escola enquanto um lugar da educação popular, indicando $\mathrm{o}$ atravessamento de fronteiras entre espaços formais e não formais. Em levantamento da ANPEd, de 190 trabalhos e pôsteres analisados entre 1999 e 2010, 31 tratavam diretamente da escola, representando acima de 16\% do total (ver Anexo: Gráfico 1). Com uma representatividade mais expressiva estavam os trabalhos classificados como teóricos, abrangendo reflexões, tais como: "O lugar da cultura no GT de educação popular da ANPED” (José Licínio Backes, 2010), "Homens e mulheres de palavra: sobre o diálogo" (Flávio Brayner, 2007), "Educação popular e experiência" (José Francisco de Melo Neto, 2010) e "Considerações iniciais sobre o conceito de educação popular na era da indeterminação" (Leandro Machado dos Santos, 2010).

Já os artigos da escola abrangem uma grande diversidade temática, desde políticas até questões metodológicas de sala de aula. O que os identifica é a visão da escola como um lugar de aprendizagem e exercício de cidadania. Vejamos alguns exemplos: "As armadilhas da capacitação e as possibilidades do trabalho em redes: reflexões sobre a participação popular na escola" (Adir da Luz Almeida, Monica Dias Peregrino e Marize Cunha, 1999), "Educação pública popular: uma análise sobre novos parâmetros de ação estatal" (Antonio Lisboa Leitão de Souza, 2003), "Escolas que somem: Reflexão sobre a Escola Pública e Educação Popular" (Maria Tereza Esteban, 2003), "Você quer o fato científico ou o que eu realmente acredito?' O conflito entre religião e a ciência nas escolas públicas municipais do Rio de Janeiro" (Lana Claudia de Souza Fonseca, 2006), "Comunidades de aprendizagem: desenvolvendo uma educação democrática e dialógica com os familiares e agentes do entorno escolar" (Fabiana Marini Braga, 2010).

Os dados anteriores não deveriam levar a uma conclusão apressada de que a educação popular migrou para a escola, deixando de lado outros lugares identificados com a sua origem, em especial os movimentos sociais populares. Muitos dos trabalhos apresentados em grupos de trabalho de movimentos sociais, ecologia, gênero, educação de jovens e adultos não deixam de ser de educação popular por serem apresentados e discutidos em círculos que criaram o seu próprio espaço. Esse fato certamente contribuiu para que houvesse, por um lado, uma concentração na escola e, por outro lado, abriu espaço para a visibilização de uma grande variedade de atores e agentes pedagógicos identificados com a educação popular. No mesmo gráfico já referido, encontramos trabalhos relacionados a processos pedagógicos em museus, em fábricas, em grupos de capoeira, em hospitais e prisões. 


\section{Tarefas emergentes}

O diálogo entre educação popular e Educação Básica permite perceber que não faz sentido qualquer tentativa de contrapor um campo ao outro, mas que ao mesmo tempo é importante mantê-los tensionados a partir da especificidade de cada um. A educação popular surge e se constitui como uma proposta pedagógica que entende o básico para além da instituição escolar e da aprendizagem de conteúdos das tradicionais disciplinas, mas não nega, em princípio, nem a instituição nem os conteúdos. Ela se encontra diante do desafio de compreender as novas institucionalidades, as novas possibilidades de lidar com o conhecimento e de constituição dos sujeitos. A Educação Básica, por seu turno, é desafiada a explicitar o seu projeto político-pedagógico em meio à diversidade do seu público e dos interesses conflitantes que se formam em torno daquilo que se entende pela formação necessária na sociedade. Deste diálogo emergem algumas tarefas comuns, entre as quais destacamos as seguintes:

Ortopráxis ou ortodoxia?

Os atuais trabalhos de pesquisa em educação popular revelam a grande diversidade de temas estudados. Isso, por um lado, é positivo na medida em que a área se abre para novas experiências, em especial para o que pode ser identificado como pedagogias encobertas pela ciência pedagógica hegemônica (STRECK, 2006). Cabem na educação popular muitos temas emergentes que talvez não encontrem espaço em áreas mais tradicionais, o que corresponde a uma das características históricas da educação popular, que foi a quebra de um pensamento ortodoxo a partir das práticas que valorizavam características culturais e sociais específicas. Com isso, amplia-se também o escopo da Educação Básica, por exemplo, trazendo à atenção os saberes da experiência que às vezes exigem longo tempo de aprendizagem.

Por outro lado, essa indefinição dificulta que em termos de pesquisa a educação popular se consolide como uma área própria e se caracterize como lugar de passagem de pesquisadores para áreas mais consolidadas. O desafio está em manter a abertura para acompanhar as mudanças na leitura da realidade sem cair no relativismo e, ao mesmo tempo, evitar uma ortodoxia que fixa diretrizes rígidas e no fim acaba inibindo a criatividade da prática. A experiência da educação popular contribui com a Educação Básica no sentido de manter presente a tensão entre teoria e prática, compreendendo a primeira como uma dimensão da própria prática que busca se compreender e recriar. 
Libertação e construção de hegemonia

Os anos iniciais da educação popular foram marcados pelo paradigma da libertação (SEMERARO, 2006) que, entre outras características, unia grupos diferentes na oposição a uma institucionalidade estatal opressora. A assunção ao poder de governos progressistas, com o apoio expresso de movimentos sociais populares e contando, muitas vezes, com lideranças surgidas desses movimentos, modifica este quadro. Criam-se, a partir desse fato, parcerias entre estado e movimentos sociais e organizações não governamentais (ONGs) de educação popular, e governos incorporam em suas políticas e práticas princípios e estratégias de educação popular. Assim, se antes a distinção entre aliados e adversários parecia relativamente simples, agora ela precisa levar em conta princípios e estratégias às vezes pouco explicitadas.

Diante deste quadro, Semeraro argumenta que se passou de um paradigma de libertação para um paradigma de hegemonia, no qual militantes políticos e educadores populares não raramente se tornam (também) gestores de projetos, políticos profissionais ou assessores de políticas públicas. Falando da realidade da Bolívia, talvez o caso mais emblemático das mudanças políticas na América Latina com a eleição de Evo Morales como presidente, Benito Fernández (2006) aponta algumas tarefas das quais a educação popular não poderia abrir mão:

a) posicionar o pensamento crítico como elemento essencial do processo pedagógico. Isso significa, entre outras coisas, não ceder aos cantos da sereia do poder e perder a capacidade de autocrítica e identificar elementos que podem ajudar a avançar o projeto;

b) desenvolver capacidades de negociação e diálogo, sem abdicar dos princípios e valores que dão sentido ao projeto de educação popular;

c) levar em conta a interculturalidade em todos os espaços e níveis de gestão e exercício de liderança;

d) promover as identidades diversas, elaborando metodologias e instrumentos adequados às respectivas práticas;

e) apoiar programas educativos massivos que abram espaço ao protagonismo do povo e suas organizações, empoderando o sujeito político;

f) desenvolver uma liderança popular que coloque os valores de mudança acima dos interesses particulares ou de grupo.

A Educação Básica, no diálogo com a educação popular, pode compreender-se mais explicitamente como um espaço político no sentido de construção de uma cidadania ativa e uma sociedade democrática, no qual permanentemente se tensiona a relação entre igualdade e diferença, cuidando para que as diferenças não se transformem em desigualdades e que a busca da igualdade não sufoque as 
diferenças. Na perspectiva da educação popular, a Educação Básica prestará especial atenção aos segmentos da sociedade - mais ou menos organizados - que buscam seu espaço como sujeitos na sociedade.

Reconstruir a memória da educação popular

A educação popular, da forma como é concebida hoje, é datada desde um pouco mais de meio século. Com isso, às vezes, ratifica-se a compreensão de que antes de Paulo Freire não existiam movimentos pedagógicos de cunho popular e emancipatório na América Latina. Disse-o muito bem Adriana Puiggrós (2010, p. 103):

Em cierto sentido, mi meta es poblar. [...] Para promover nuevos sujetos em la arrasada tierra de la educación latinoamericana, no es suficiente convocar a las nuevas generaciones. Es necesario nombrar las del pasado, reubircarlas y reubicarnos frente a ellas o con ellas. Solo así lograremos que el espectro de um pasado irresuelto se torne sedimento productivo para la continuidad de nuestra historia.

Antes da chegada dos conquistadores europeus, houve pedagogias em Abya Yala, nome que os povos originários preferem usar para designar nosso subcontinente. Ou seja, o deserto já não existia quando da chegada dos europeus. Além disso, durante séculos, criaram-se estratégias pedagógicas que garantiram a sobrevivência e a resistência. Algumas delas, surgidas no anonimato de grupos e movimentos, passaram a fazer parte de uma memória coletiva de enfrentamento da opressão. Outras, em diálogo com a tradição europeia, ora apropriando-se de seus conceitos, ora os negando ou ressignificando, buscaram elaborar propostas adequadas à formação dos sujeitos e das sociedades nesta parte do mundo. ${ }^{8}$

Esse fato é de grande relevância para a constituição de uma matriz pedagógica que permite desenvolver políticas e práticas de Educação Básica arraigadas na cultura do povo, evitando migrar de reforma em reforma sem alcançar os resultados desejados. Há mais de um século, José Martí (2007, p. 103) advertia que "as reformas só são fecundas quando penetram no espírito dos povos e escorregam por sobre eles como a areia seca sobre as rochas inclinadas, quando a rudeza, sensualidade ou egoísmo da alma pública resistem ao influxo melhorador das práticas que só acata em forma e nome". Martí se debatia pelo sonho ainda vivo de uma educação ao mesmo tempo enraizada em nossa América e cosmopolitanamente aberta.

\footnotetext{
${ }^{8} \mathrm{O}$ livro Fontes da pedagogia latino-americana: uma antologia (STRECK, 2010) reúne 26 textos-fonte de autores latino-americanos.
} 
Aprofundamento metodológico

$\mathrm{Na}$ educação popular, seguindo o pensamento de Paulo Freire, o ato de ensinar-aprender e o ato de pesquisar são duas faces do mesmo processo de conhecer. Este ocorre entre sujeitos que, numa relação dialógica, propõem a sua realidade - que significa também a sua consciência desta realidade - como objeto de conhecimento e de transformação. A Educação Básica, com sua diversidade de práticas e contextos, pode integrar-se nesse movimento de reconstrução metodológica.

Cabem aqui três tarefas complementares:

a) realizar uma recuperação histórica de práticas de pesquisa que geraram o que hoje conhecemos como pesquisa participante. Isso se refere a experiências na América Latina, mas se refere também a experiências em outros continentes, onde pesquisadores realizavam trabalhos com a mesma intencionalidade e com semelhantes ferramentas;

b) aprofundar, a partir de práticas de pesquisa, a reflexão sobre conceitos chaves da educação popular e das metodologias participativas de pesquisa. Na maioria das vezes, anuncia-se o uso desse tipo de metodologia, mas não se volta a ela junto com a discussão dos resultados;

c) desenvolver e apropriar-se de ferramentas que permitam uma aproximação criativa da realidade a ser estudada. As experiências de sistematização são uma importante fonte geradora de novas ferramentas.

Articulação de pesquisas e estudos

Por fim, a pesquisa em educação popular compartilha o problema que Charlot (2006) aponta para a área da educação em geral: a carência de memória. É difícil não concordar com ele quando afirma que "a principal consequência disso é que refazemos continuamente as mesmas teses, as mesmas dissertações, sem sabermos o que foi produzido anteriormente" (CHARLOT, 2006, p. 17). Às vezes, tem-se a impressão que a revisão de estudos sobre determinado tema torna-se mais rasa na mesma proporção que crescem as pesquisas e os instrumentos para acessar informações.

Provavelmente, teria muito pouco efeito criar mais um espaço para disponibilizar os trabalhos em educação popular, inclusive pela diversidade de lugares e de sujeitos de produção de conhecimentos na área. Uma possibilidade à mão é potencializar o funcionamento de lugares já disponíveis - como a ANPEd e o CEAAL - para realizar tarefas coletivas, entre elas: discutir agendas de pesquisa; fomentar a criação de redes de pesquisa em educação popular; realizar fóruns temáticos de educação popular com temas específicos ou em conjunto com outras áreas de pesquisa. 
Ainda que de forma fragmentada, a pesquisa em educação popular trouxe, como vimos ao longo deste trabalho, uma importante contribuição para a compreensão atual de Educação Básica: ampliou o conceito, integrou novos lugares e novas práticas, e promoveu metodologias dialógicas no ensino e na pesquisa. Talvez seja pouco em vista dos desafios que a sociedade atual experimenta, quando o "básico" que sustenta a prática de cada um e cada uma de nós é posto sob suspeição e quando sob o manto de verdades provisórias se gestam consensos sobre um único mundo possível.

\section{Referências}

ADAMS, T. A pesquisa participativa como mediação pedagógica da educação popular. In: REUNIÃO ANUAL DA ANPED, 32., 2009, Caxambu. Anais... Caxambu: ANPEd, 2009. p. 1-13.

ADAMS, T.; STRECK, D. Pesquisa em educação e colonialidade: os movimentos sociais e a reconstrução epistemológica. In: SEMINÁRIO DE PESQUISA EM EDUCAÇÃO DA REGIÃO SUL - ANPEDSUL, 8., 2010, Londrina. Anais... Londrina: UEL/PR, 2010. p. $1-17$.

ALTHUSSER, L. Ideologia e aparelhos ideológicos do Estado. 6. ed. Rio de Janeiro: Graal, 1992.

AMÂNCIO, C. Educação popular e intervenção comunitária: contribuições para a reflexão sobre empoderamento. In: REUNIÃO ANUAL DA ANPED, 27., 2004, Caxambu. Anais... Caxambu: ANPEd, 2004. p. 1-17.

AZEVEDO, J. C.; GENTILI, P.; KRUG, A.; SIMON, C. (Orgs.). Utopia e democracia na educação cidadã. Porto Alegre: Ed. da Universidade-UFRGS, 2000.

AZIBEIRO, N. E.; PERASSA, I. M. Entrelaços do saber: produção coletiva de conhecimentos, empowerment e inclusão social. In: SEMINÁRIO DE PESQUISA EM EDUCAÇÃO DA REGIÃO SUL - ANPEDSUL, 5., 2004, Curitiba. Anais... Curitiba: PUC/PR, 2004. p. 1-15.

BAGGIO, F. S. F. Movimento de Participação popular na constituinte. Curitiba: Gráfica Popular: CEFURIA, 2006.

BARBOSA, L. R. Movimento de Cultura Popular: impactos na sociedade pernambucana. Recife: Ed. do Autor, 2009.

BOURDIEU, P.; PASSERON, J. C. A reprodução: elementos para uma teoria do sistema de ensino. 2. ed. Rio de Janeiro: Francisco Alves, 1982.

BRANDÃO, C. R. Da educação fundamental ao fundamental da educação. Proposta, set. 1977, Suplemento 1.

(Org.). De Angicos a Ausentes: 40 anos de educação popular. Porto Alegre: MOVA/RS; CORAG, 2001.

A educação popular na escola cidadã. Petrópolis RJ: Vozes, 2002.

A pesquisa participante e a participação da pesquisa: Um olhar entre tempos e espaços a partir da América Latina. BRANDÃO, C. R.; STRECK, D. R. Pesquisa participante: o saber da partilha. Aparecida: Ideias \& Letras, 2006. p. 21-54. 
BRANDÃO, C. R.; STRECK, D. R. Pesquisa participante: o saber da partilha. Aparecida: Ideias \& Letras, 2006.

BRASIL. Lei no 9.394, de 20 de dezembro de 1996. Estabelece as Diretrizes e Bases da Educação Nacional. Diário Oficial da União, Brasília, 23 dez. 1996.

BRAYNER, F. Educação Popular: pela recuperação da "AÇÃO e do "SENSO COMUM". In: REUNIÃO ANUAL DA ANPED, 31., 2008, Caxambu. Anais... Caxambu: ANPEd, 2008. p. 1-13.

CAMPOS, M. M. Para que serve a pesquisa em educação? Cadernos de pesquisa, São Paulo: Fundação Carlos Chagas; Campinas: Autores Associados, v. 39, n. 136, p. 269-283, jan./abr. 2009.

CÉSPIDES, N. Educación popular y calidad educativa. La Pirágua, n. 22, p. 19-24, 1/2005.

CHARLOT, B. A pesquisa educacional entre conhecimentos, políticas e práticas: especificidades e desafios de uma área de saber. Revista Brasileira de Educação, Rio de Janeiro, v. 11, n. 31, p. 7-18, jan/abr. 2006.

COSTA, M. V.; FLEURI, R. M. Travessia: questões e perspectivas emergentes na pesquisa em Educação Popular. Ijuí: Unijuí, 2001.

CUNHA, A. L de. Caminhos metodológicos para o diálogo com mulheres negras que aprendem/ensinam artesanato: educação popular e feminilidades. In: REUNIÃO ANUAL DA ANPED, 32., 2009, Caxambu. Anais... Caxambu: ANPEd, 2009. p. 1-5.

Declaração de Jomtien (Tailândia). 09 de Março de 1990. Disponível em: < http://www. pitangui.uepg.br/nep/documentos/Declaracao\%20-\%20jomtien\%20-\%20tailandia.pdf $>$. Acesso em: 03 abr. 2012.

DELORS, J. Educação: um tesouro a descobrir. 2. ed. São Paulo: Cortez, 1999.

FALCHEMBACH, E. M. Sistematização em educação popular: uma história, um debate... In: REUNIÃO ANUAL DA ANPED, 30., 2007, Caxambu. Anais... Caxambu: ANPEd, 2007. p. 1-18.

FALS BORDA, O. Antología. Bogotá: Universidad Nacional de Colombia, 2010.

FÁVERO, O. Uma pedagogia da participação popular: análise da prática educativa do MEB - Movimento de Educação de Base (1961/1966). Campinas: Autores Associados, 2006.

FERNÁNDEZ, B. Educación popular y nueva hegemonia. In: CEPROTAC. Tareas de la educación popular em la revolución democrática y cultural. La Paz: CEPROTAC, 2006. p. $55-68$.

FREIRE, P. Educação como prática da liberdade. 11. ed. Rio de Janeiro: Paz e Terra, 1980.

Pedagogia do oprimido. 9. ed. Rio de Janeiro: Paz e Terra, 1981.

Educação na cidade. São Paulo: Cortez, 1991.

GADOTTI, M. Escola cidadã, cidade educadora projetos e práticas em processo. Fórum Mundial de Educação São Paulo. Revista do Programa de Pós-Graduação em Arquitetura e Urbanismo da FAUUSP, São Paulo, n. 14, p. 130-139, dez. 2003. 
GONÇALVES, L. G. Uma reinvenção dos saberes imemoriais nos contos de investigação criminal. In: REUNIÃO ANUAL DA ANPED, 26., 2003, Poços de Caldas. Anais... Poços de Caldas: ANPEd, 2011. p. 1-13.

GONSALVES, E. P. A difícil arte de olhar para si e para o outro: desafios contemporâneos da pesquisa em educação. In: REUNIÃO ANUAL DA ANPED, 24., 2001, Caxambu. Anais... Caxambu: ANPEd, 2001. p. 1-11.

HARPER, B. Cuidado, escola! Desigualdade, domestição e algumas saídas. São Paulo: Brasiliense, 1980.

ILLICH, I. Sociedade sem escolas. 2. ed. Petrópolis: Vozes, 1973.

JARA. O. Sistematização de experiências: algumas apreciações. In: RODRIGUES, C.; STRECK, D. R. (Orgs.). Pesquisa participante: o saber da partilha. Aparecida: Ideias \& Letras, 2006. p. 227-244.

KIELING, J. F. Investigando e agindo com professores e escolas do campo: esboço dos fundamentos epistemológicos apropriados para a construção curricular em escolas do campo através da investigação do modo de ser e produzir das comunidades camponesas (dos colonos). In: SEMINÁRIO DE PESQUISA EM EDUCAÇÃO DA REGIÃO SUL ANPEDSUL, 5., 2004, Curitiba. Anais... Curitiba: PUC/PR, 2004. p. 1-12.

LAMBACH, M. A sociogênese do conhecimento científico relacionada à educação libertadora. In: SEMINÁRIO DE PESQUISA EM EDUCAÇÃO DA REGIÃO SUL - ANPEDSUL, 6., 2006, Santa Maria. Anais... Santa Maria: UFSM/RS, 2006. p. 1-7.

MACHADO, R. C.; PALUDO, C. A sistematização como um dos métodos da educação popular. In: SEMINÁRIO DE PESQUISA EM EDUCAÇÃO DA REGIÃO SUL ANPEDSUL, 8., 2010, Londrina. Anais... Londrina: UEL/PR, 2010. p. 1-11.

MARTÍ, J. Educação em nossa América: textos selecionados. Organizado e apresentado por Danilo R. Streck. Ijuí: Unijuí, 2007.

MEJÍA, M. R.; AWAD, M. I. Educación popular hoy: en tiempos de globalización. Bogotá: Aurora, 2007.

MELO NETO, J. F de. Educação popular e experiência. In: REUNIÃO ANUAL DA ANPED, 33., 2010, Caxambu. Anais... Caxambu: ANPEd, 2010. p. 1-17.

MORETTI, C. Z. Fontes da educação popular e da pesquisa participativa na América Latina: epistemologias ao sul da colonialidade do conhecimento. In: REUNIÃO ANUAL DA ANPED, 33., 2010, Caxambu. Anais... Caxambu: ANPEd, 2010. p. 1-15.

PAIVA, M. M. (Org.). Escolas radiofônicas de Natal: uma história construída por muitos (1959-1966). Brasília: Liber, 2009.

PALUDO, C. Educação popular em busca de alternativas: uma leitura desde o Campo Democrático e Popular. Porto Alegre: Tomo; CAMP, 2001.

PERESSON.; M. L. Educar desde las culturas populares. Bogotá: Família Salesiana, 1994.

PUIGGRÓS, A. De Simón Rodríguez a Paulo Freire: educación para la integración iberoamericana. Buenos Aires: Colihue, 2010. 
RODRIGUES, I. N.; CASTRO, T. F. Uma experiência de formação de educadores na perspectiva intercultural: problematização acerca da investigação-ação. In: REUNIÃO ANUAL DA ANPED, 28., 2005, Caxambu. Anais... Caxambu: ANPEd, 2005. p. 1-5.

RODRIGUEZ, L. L. Investigação e mudança. In: SEMINÁRIO DE PESQUISA EM EDUCAÇÃO DA REGIÃO SUL - ANPEDSUL, 5., 2004, Curitiba. Anais... Curitiba: PUC/PR, 2004. p. 1-13.

RODRÍGUEZ, S. La defensa de Bolívar. Caracas: Ediciones Rectorado, 2006.

ROJAS GUERRA, J. M. Sobre la fundación de la sociologia em Colombia (Prefacio). FALS BORDA, Orlando. Antología. Bogotá: Universidad Nacional de Colombia, 2010, p. IX LIII.

SALES, S. Relação entre governos e sociedade civil organizada e a produção de políticas: contribuições do Movimento de Alfabetização de Jovens e Adultos (Mova). In: SANTOS, R. E.; ALVARENGA, M. S.; NOBRE, D.; ALENTEJANO, P. (Orgs.). Educação popular, movimentos sociais e formação de professores: diálogos entre saberes e experiências brasileiras. Petrópolis: DP et Alii; Rio de Janeiro: FAPESP, 2010. p. 55-66.

SEMERARO, G. Libertação e hegemonia: chaves de filosofia política na educação brasileira. In: TORRES, A., SEMERARO, G.; PASSOS, L. A. Educação: fronteira política. Cuiabá: Ed. UFMT, 2006. p. 19-36.

STRECK, D. R. A educação popular e a (re)construção do público. Há fogo sob as brasas? Revista Brasileira de Educação, Rio de Janeiro, v. 11, n. 32, p. 272-284, ago. 2006. DOI: 10.1590/S1413-24782006000200006 2010.

Fontes da pedagogia latino-americana: antologia. Belo Horizonte: Autêntica,

TAVARES, M. T. G. "A chegada da estranha”: desafios político-epistemológicos da pesquisa com as camadas populares. In: REUNIÃO ANUAL DA ANPED, 32., 2009, Caxambu. Anais... Caxambu: ANPEd, 2009. p. 1-14.

TORRES CARRILLO, A. La educación popular: trajectoria y actualidad. Bogotá: El Buho, 2007.

Generating knowledge in popular education: from participatory research to the systematization of experiences. International Journal of Action Research, v. 6, n. 2-3, p. 196-222, 2010.

WANDERLEY, L. E. W. Educação popular: metamorfoses e veredas. São Paulo: Cortez, 2010.

WERLE, F. Educação Básica: a dimensão do legal e do concreto. STRECK, D. (Org.). Educação Básica e o básico na educação. Porto Alegre: Sulina; São Leopoldo: Unisinos, 1996. p. 68-90.

WUNDER, A. Registros em narrativas: experiências de uma pesquisa participante nas interfaces entre a palavra e a imagem. In: REUNIÃO ANUAL DA ANPED, 26., 2003, Poços de Caldas. Anais... Poços de Caldas: ANPEd, 2003. p. 1-6. 


\section{Anexo}

Gráfico 1 - Lugares da educação popular (ANPEd, 1999-2010)

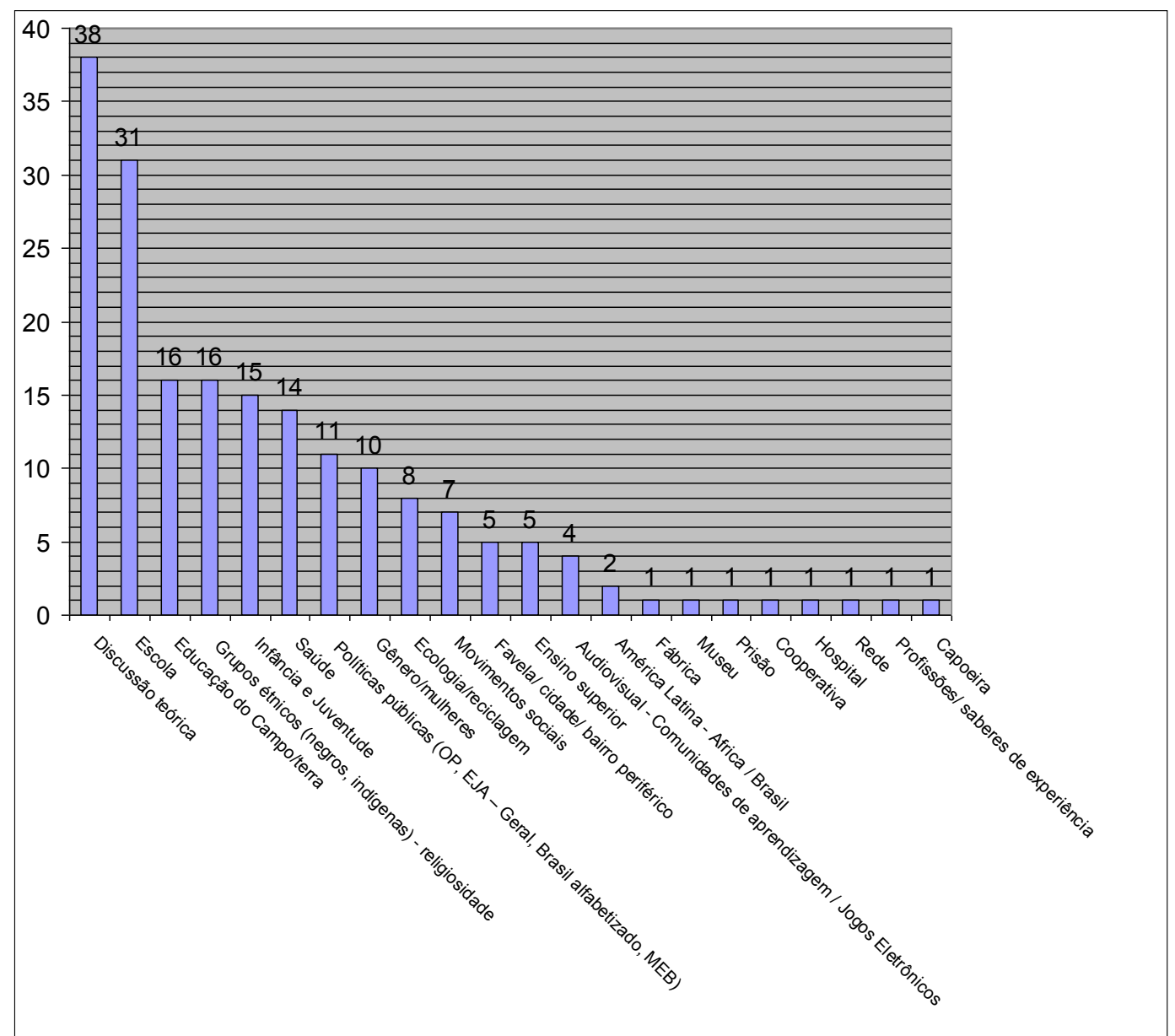

Fonte: $\mathrm{O}$ autor.

Nota: Foram analisados 190 trabalhos e pôsteres apresentados no GT de Educação Popular da ANPEd, no período de 1999 a 2010.

Recebido em 15/08/2012

Aceito em 19/11/2012 